\title{
Seasonal and interannual variability of phytoplankton abundance and community composition on the Central Coast of California
}

Alex Barth ${ }^{1}$, Ryan K. Walter ${ }^{2}$, Ian Robbins ${ }^{2}$, Alexis Pasulka ${ }^{1, *}$

${ }^{1}$ Biological Sciences Department, California Polytechnic State University, San Luis Obispo, CA 93407, USA

${ }^{2}$ Physics Department, California Polytechnic State University, San Luis Obispo, CA 93407, USA

ABSTRACT: Variations in the abundance and composition of phytoplankton greatly impact ecosystem structure and function. Within the California Current System (CCS), phytoplankton community structure is tightly coupled to seasonal variability in wind-driven coastal upwelling, a process that drives changes in coastal water temperatures and nutrient concentrations. Based on approximately a decade (2008-2018) of weekly phytoplankton measurements, this study provides the first characterization of the seasonal and interannual variability of phytoplankton abundance and composition in San Luis Obispo (SLO) Bay, an understudied region within the CCS. Overall, the seasonality of phytoplankton in SLO Bay mirrored that of the larger CCS; diatoms dominated the community during the spring upwelling season, whereas dinoflagellates dominated the community during the fall relaxation period. While we observed considerable interannual variability among phytoplankton taxa, of particular note was the absence of a fall dinoflagellate-dominated period from 2010 through 2013 , followed by the return of the fall dinoflagellate-dominated period in 2014. This compositional shift coincided 
with a major phase shift of both the Pacific Decadal Oscillation (PDO) and North Pacific Gyre Oscillation (NPGO). In addition to exerting a strong influence on the seasonality of phytoplankton community succession and transition between diatom- and dinoflagellate-dominated periods, the state of both the PDO and NPGO also influenced the extent to which environmental conditions (temperature and upwelling winds) could predict community type. These results highlight the importance of long-term datasets and the consideration of large-scale climate patterns when assessing local ecosystem dynamics.

KEYWORDS: Phytoplankton, Harmful algal bloom, Diatoms, Dinoflagellates, Pacific Decadal Oscillation, North Pacific Gyre Oscillation

\section{INTRODUCTION}

The structure and function of phytoplankton communities directly impact higher trophic levels and key biogeochemical cycles in the ocean. Due to variations in the functional ecology of different phytoplankton taxa (e.g. Litchman et al. 2007, Litchman \& Klausmeier 2008), it is critical to understand how environmental conditions alter phytoplankton community composition and in turn ecosystem function, particularly in a changing climate. Many different frameworks have been used to integrate oceanographic variability with changes at the base of the food web over different time and space scales (e.g. Sverdrup 1953, Margalef 1978, Longhurst 1995). In eastern boundary current coastal upwelling systems, like 
the California Current System (CCS), the seasonal succession of phytoplankton taxa is commonly attributed to variations in upwelling intensity, which alter nutrient input and water column stability (Margalef 1978, Checkley \& Barth 2009, Walter et al. 2018). The nutrient-rich waters in the spring upwelling season are typically dominated by large, chain-forming diatoms (Schrader 1981, Venrick 1998, Anderson et al. 2008), whereas the nutrient-limited waters and increased water column stability during the fall upwelling relaxation season favor dinoflagellates (Schrader 1981, Keating 2013, Du \& Peterson 2014). This type of framework allows for theprediction of canonical patterns of phytoplankton abundance and composition over time and space; however, deviations from these patterns can provide insight into ecosystem functioning in response toenvironmental change.

Specifically, temporal fluctuations in the abundance and composition of diatoms and dinoflagellates have ecosystem-wide consequences. These groups differ in their trophic ecology, impact on biogeochemical cycles, and influence on harmful algal bloom (HAB) dynamics (Aberle et al. 2007, Koski etal. 2008, Trainer et al. 2010). In fact, changes in the ratio of these two groups have been used in a variety of ecosystems as an indicator of both shortterm and long-term environmental change (McQuatters-Gollop et al. 2007, Wasmund et al. 2017, Spilling et al. 2018) and can be linked to local processes such as eutrophication (Heisler et al. 2008), regional processes like upwelling/relaxation cycles and upwelling seasonality (Kudela et al. 2005), or largerscale processes such as climate oscillations (Du et al.2015). While 
studies that investigate the complex interplay between phytoplankton and environmental conditions over shorter time periods can be key to understanding local dynamics, longer-term studies that characterize the relative abundance of phytoplankton over seasonal and interannual timescales are critical for assessing the impact of regional and basin-scale climate events on the structure and function of local ecosystems.

In this study, we take advantage of a decade (2008-2018) of weekly phytoplankton measurements collected in a small, semi-enclosed coastal embayment along the Central Coast of California at the California Polytechnic State University (Cal Poly) Pier. These measurements were collected as part of a $\mathrm{HAB}$ monitoring program, and comprise the first long-term synthesis of phytoplankton community structure in the region. Seasonal and interannual variability in phytoplankton abundance and composition were investigated to assess how local nearshore phytoplankton dynamics are influenced by both regional and basinscale oceanographic variability. In addition to exploring the variability of some of the most abundant phytoplankton taxa (grouped at the genus level) in our region, we examined the ratio of diatoms to dinoflagellates over seasonal and interannual time-scales. This long-term dataset provided a unique opportunity to look at deviations from canonical patterns and to link these changes to local environmental variability and largescale ocean climate variability.

2. MATERIALS AND METHODS

2.1. Sample and data collection 


\subsubsection{Sampling site}

Phytoplankton measurements were collected as part of the Southern California Coastal Ocean Observing System (SCCOOS) HABs monitoring program. Surface samples were collected weekly or biweekly from August 2008 to December 2018 (see Section 2.2.1 and Fig. S1 in the Supplement at www.int-res.com/articles/suppl/m637p029_supp.pdf for sampling resolution details) using a bucket at the end of the Cal Poly Pier in San Luis Obispo (SLO) Bay $\left(35.170^{\circ} \mathrm{N}, 120.741^{\circ} \mathrm{W}\right)$. All of the data used for this study can be accessed through the SCCOOS data portal: http://erddap.sccoos.org/erddap/tabledap/HABsCalPoly.html. SLO Bay is a semi-enclosed coastal embayment located along the central coast of California, a relatively understudied region of the California Current System (CCS). Moreover, this region has experienced a large number of deleterious HAB events, resulting in periodic marine mammal stranding and the appearance of paralytic shellfish poison (PSP) toxin (Greig et al. 2005, Bejarano et al. 2008, Lewitus et al. 2012).

\subsubsection{Phytoplankton composition and abundance}

To measure phytoplankton abundance, $100 \mathrm{ml}$ of surface water was preserved with formalin (3.7\% final concentration) for transport and analysis in the lab. Phytoplankton were identified and enumerated using the Utermöhl method (Edler \& Malte 2010). In short, after settling $25 \mathrm{ml}$ of sample, individual cells were counted across 10 fields of view on an inverted microscope (Olympus IX70-S8F2) using either a 10' or 20’ objective. On 
average, only phytoplankton cells $>20 \mu \mathrm{m}$ in size were identified to the highest taxonomic level possible. However, some species whose size is smaller but which form chains were also identified and counted. For chains, the cells within an individual chain were enumerated. Overall phytoplankton concentration $(C)$ was calculated from count data following Edler \& Malte (2010),

[Insert Equation 1]

where $N$ is the number of cells, $A$ is the area of the settling chamber, $V$ is the volume settled, $F$ is the number of fields of view, $A F$ is the area for field of view, and $D$ is the dilution factor. This equation(Eq. 1) takes into account variations in the volume counted between different objectives. See Section 2.2.1 for a more detailed discussion of long-term datasets, potential biases, and data management.

2.1.3. Chlorophyll $a(\operatorname{chl} a)$ analysis

Chl $a$ samples were collected in replicate from the same water as phytoplankton samples, filtered $(25 \mathrm{ml})$ onto Whatman GF/F filters, immediately frozen for transport back to the lab, and stored at $-80^{\circ} \mathrm{C}$ until further analysis. Chl $a$ was extracted in $90 \%$ acetone and measured on a 10AU Turner fluorometer using the acidification method (Strickland \& Parsons 1972).

\subsubsection{Environmental data}

Hourly offshore wind measurements were obtained from the National Data Buoy Center Buoy 46011 located $\sim 35 \mathrm{~km}$ offshore of SLO Bay 
(https://www. ndbc.noaa.gov). Equatorward upwelling-favorable winds were computed using the local coastline orientation ( $150^{\circ}$ from true north), and upwelling-favorable wind stresses (where positive = upwelling-favorable, negative $=$ downwelling-favorable) were calculated following Large $\&$ Pond (1981). Surface seawater temperature measurements were obtained every $\sim 30$ minfrom an automated profiling system located at the end of the Cal Poly Pier (see Walter et al. 2018 for configuration and sampling details; www.cencoos.org/ data/shore/sanluis). Surface temperature data were vertically averaged from downcast data between 1 and $1.5 \mathrm{~m}$ depth. For both temperature and upwelling-favorable wind stress, annual average variability was quantified by computing averages from all available data for a particular month. For assessing interannual trends, we retained averages from individual months over all years. To assess the relationship between measured interannual trends and basin-scale oceanographic variability, we obtained the Pacific Decadal Oscillation (PDO) index (https://oceanview.pfeg.noaa.gov/erddap/tabledap/cciea_OC_PDO.html) and the North Pacific Gyre Oscillation (NPGO) index (www.o3d.org/npgo/npgo.php).

\subsection{Data analysis}

\subsubsection{Data filtering and management}

While long-term monitoring programs are important for capturing the relationships between phytoplankton community dynamics and environmental conditions over seasonal and interannual timescales, these datasets are subject to inherent biases such as observer-bias (e.g. Peperzak 
2010). To account for these biases and analyze the data in a robust manner, we (1) controlled the data quality, (2) examined biases within the data, (3) binned the data at lower taxonomic levels (e.g. summed data to genuslevel) to remove biases, and (4) focused our analyses and conclusions on longer time-scale processes (e.g. mean seasonal and interannual patterns) rather than episodic events. First, to quality-control the data prior to analysis, historical records of phytoplankton abundance were vetted for accuracy. All digital data were closely examined, and any obvious transcription errors (e.g. date errors and unrealistically high counts or chl $a$ concentrations) were cross-checked and corrected according to the dry logs. While samples were collected regularly (weekly or biweekly) from 2008 to 2018, with lower sampling frequency in 2012 and missing data from 2011, the final dataset comprised 529 samples (Fig. S1). Second, we examined biases in our dataset associated with variations in observer and/or microscope objective. Nonmetric multidimensional scaling (NMDS) and an assessment of genera richness over time were used to determine if changes in observer (and/or microscope objective) resulted in significant changes in the composition and/or number of genera detected, respectively (Peperzak 2010). In addition to the fact that species identification can vary between individuals, morphological datasets derived from light microscopy can also miss cryptic species. Therefore, all data were summed to the genera level (see Section 2.2.2 for more details) and for some analyses the taxa level (e.g. diatom vs. dinoflagellate). Finally, while sampling typically occurred on a weekly 
basis, the variation in sampling effort prohibited reliable investigation of episodic events. Therefore, to investigate long-term patterns, counts were aggregated into monthly, yearly, or annual averages, using reliable taxonomic categories (see Section 2.2.2). All data were managed and analyzed using R 3.4.2 (R Core Team 2017) and MATLAB 2019a (v. 9.6).

\subsubsection{Phytoplankton community analysis}

As discussed above, all taxa were summed to the genera level to account for variation in the taxonomic specificity identified. For this analysis, phytoplankton were distinguished into 9 particular genera that are morphologically distinct, identified as part of the SCCOOS monitoring program, and are persistent members of the community along the California coast: Alexandrium, Dinophysis, Lingulodinium, Akashiwo, Prorocentrum, Pseudo-nitzschia, Chaetoceros, Ceratium, and Cochlodinium (Curtiss et al. 2008, Jester et al. 2009, Trainer et al. 2010). All other genera that were counted were grouped more broadly as either 'other dinoflagellates' or 'other diatoms.'

Phytoplankton abundance was averaged across various time scales to investigate both seasonal and interannual variability. To determine seasonal patterns, monthly averages were calculated using data across all years for a particular month (i.e. 'average year'). The monthly ratio of dinoflagellates to diatoms was calculated by using the monthly average abundance of each category. Relative abundance at the average seasonal scale was calculated for the 9 genera and additionally 'other dinoflagellates' and 'otherdiatoms' by 
dividing the sum of each group's abundance in a given month by the total abundance (cells $1^{-1}$ ) summed across the 11 categories ( 9 genera and 2 'other' groups) for that particular month. To investigate interannual trends, all measurements of phytoplankton abundance were averaged withinindividual months over all years. Annual changes in the relative abundance were calculated by dividing the sum of abundance for each group by the total yearly abundance. For phytoplankton abundance and chlorophyll concentration averages, empirical bootstraps (1000 repetitions) were used to obtain $95 \%$ confidence intervals.

\subsubsection{Quantitative linkages to physical environment}

Each month (across all years) was plotted in the parameter space of upwelling-favorable wind stress and sea surface temperature to investigate the interactive effect of these two variables on phytoplankton community composition. A k-means clustering analysis was conducted using these two parameters (upwelling wind and temperature) to investigate how well these variables could explain the likelihood that a given month was diatom- or dinoflagellate-dominated. A k-means clustering analysis starts with a fixed number of clusters $(\mathrm{k})$ and starting configuration of cluster centers. The analysis proceeds by assigning objects to clusters and iteratively optimizing the object sets such that the within-cluster sum of squares distance is minimized relative to the cluster center (Lance \& Williams 1967, MacQueen 1967). Clustering analyses were also conducted with the data separated based on the mean long-term state of both the PDO and NPGO. For the NPGO, a 
shift froma positive mean state to a negative mean state occurred on October 2013, and for the PDO, a shift from a negative mean state to a positive mean state occurred on January 2014 (see Fig. 3). In total, 5 k-means cluster analyses were conducted with the diatom-dinoflagellate ratio in the upwelling wind and temperature parameter space ( 1 with the entire data set and 4 that were based on data separated by the state of climate indices — both phases of the PDO andNPGO, respectively). Once clusters were identified, a 1-tailed, exact binomial test was used to compare the probability that a community in each cluster could be significantly identified as either dinoflagellate- or diatom-dominated, relative to an equal probability (50\%) of one occurring. The directionality of these 1-tailed tests was selected individually for each cluster based on which community type was more prevalent.

Additionally, to further investigate the influence of large-scale climatic oscillations on community structure, the PDO and NPGO index were compared to the average monthly diatom-dinoflagellate ratio. Simple linear regressions were constructed with the monthly ratio of dinoflagellates to diatoms as the response, and climate index as the predictor variable. The actual numeric value of both the NPGO and PDO were used for this analysis; therefore, it is important to note that an individual month can deviate in sign from the long-term mean state of the index as used in the clustering analysis. Because this is a highly seasonal environment, simple linear regressions were also constructed for each upwelling season separately (see Walter et al. 2018 for a discussion of the upwelling seasonality framework tuned for this 
particular region). For each regression analysis, a Durbin-Watson test was used to check for autocorrelation of errors. If significant autocorrelation was identified in the model, an HAC estimator was used (Zeileis 2004).

\section{RESULTS}

3.1. Seasonal variability

\subsubsection{Environmental data}

Seasonal variability over an average year in SLO Bay was characterized by changes in upwelling-favorable wind stress resulting in variability in near-surface temperature, phytoplankton biomass (as indicated by chl $a$ ), and phytoplankton abundance and composition (Fig. 1). To link the physical forcing with changes at the base of the food web over the average year, we adopted the seasonal framework developed by Walter et al. (2018) for SLO bay which considers both the mean and standard deviation of the upwelling-favorable wind stress calculated across all years for a particular month (Fig. 1D; see also García-Reyes \& Largier 2012). These seasons include the winter storms season (December-February), the peak upwelling season (April-May), and the upwelling relaxation period (July-September), with March and June representing upwelling transition months and October and November representing winter transition months. The average nearsurface temperature at the study site was strongly coupled to seasonal changes in the upwelling wind stress (Fig. 1C; Walter et al. 2018). The winter storms season had moderate average near-surface temperatures $\left(\sim 13^{\circ} \mathrm{C}\right)$ with low variability. During the March upwelling transition, average near-surface 
temperature declined but increased in variability. Average temperatures reached a minimum $\left(\sim 12^{\circ} \mathrm{C}\right)$ during the peak upwelling season and began to increase again throughout the upwelling relaxation period, reaching a maximum in September $\left(\sim 16^{\circ} \mathrm{C}\right)$ with the largest variability. Temperatures declined again going intothe winter transition season.

\subsubsection{Phytoplankton community data}

An assessment of genera richness (e.g. total genera) over time revealed that samples analyzed with a $20^{\prime}$ objective detected on average fewer genera than those analyzed with a 10' objective (Fig. S2A). However, it is important to note that changes in genera richness are also an artefact of changes in the number of genera identified as part of this monitoring program. Prior to July 2013, 70 genera were identified, but 11 additional genera ( 81 in total) were identified after July 2013. Together, these findings support the importance of pooling the data into the 11

[Insert Figure 1]

categories listed in Section 2.2.2, which are easily identifiable at both 10' and 20'. An NMDS analysis of this pooled data revealed no significant impact of methodology (e.g. observer or microscope objective) on community composition patterns (Fig. S2B).

The phytoplankton community in SLO Bay exhibited strong seasonality shifting from a diatom-dominated community in the spring and summer to a dinoflagellate-dominated community in the fall and early winter (Fig. 1A). The transition from a diatom-dominated community to a dinoflagellate- 
dominated community occurred in September for the average year. Average surface chl $a$ concentration showed strong seasonality, reaching a peak in late fall (October; Fig. 1B).

The composition of major taxa within the diatom and dinoflagellate communities also varied seasonally(Fig. 2). During peak upwelling in the spring, the diatom community was dominated by Chaetoceros spp. The relative abundance of Chaetoceros spp. declined during the June upwelling transition period and the community was composed of a number of different 'other diatoms.' Throughout the upwelling relaxation season (August to September), Pseudonitzschia spp. increased their relative abundance to the total diatom community. In September, diatom and dinoflagellate communities were in equal proportions to one another, with Cochlodinium spp. composing a large portion of the dinoflagellate community.

[Insert Figure 2]

As dinoflagellate abundance peaked in the winter transition season (October-November), Cochlodinium spp. remained a large portion of the total community, while 'other dinoflagellates' also increased in proportion. By December, although total dinoflagellate abundance was low (Fig. 1A), the dinoflagellates Alexandrium spp. and Ceratium spp. accounted for alarge portion of the total community (Fig. 2).

\subsection{Interannual variability}

The phytoplankton community exhibited interannual variability across the 10-year time series (Figs. $3 \& 4$ ). Of particular note, the late fall 
appearance of a dinoflagellate-dominated community was nearly absent from 2009 through 2014 (Fig. 3A). While dinoflagellates were consistently present during this period, they were reduced in numbers and typically lower than diatom densities (Fig. S3). The 10-year time period in this study spanned a shift in the PDO from a predominantly cool (negative) phase to a predominantly warm (positive) phase around January 2014 and a shift in the NPGO froma predominantly positive to a predominantly negative phase 3 moprior (approximately October 2013; Fig. 3B,C). The timing of the shift in these climatic indices coincides with the reappearance of the late fall dinoflagellate-dominated periods. Starting in 2014, there was a resurgence of dinoflagellate-dominated periods during the fall upwelling relaxation season, typically between July and September (Fig. 3). However, it was not until 2016 that dinoflagellates accountedfor at least half of the year's total phytoplankton abundance (Fig. 4). Following 2016, the monthly total dinoflagellate abundance increased even more, particularly during the fall relaxation and winter transition seasons (Fig. S3).

There was also interannual variability in the composition within both the diatom and dinoflagellate communities (Fig. 4). From 2009 to 2013, Chaetoceros spp. accounted for a large portion of the diatom community, while in 2013 and

[Insert Figure 3] 2014, Pseudo-nitzschia spp. composed a larger portion of the diatom community (Fig. 4). The fall dinoflagellate-dominated community was 
composed largely of Cochlodinium spp., Lingulodinium spp., and Prorocentrum spp. with 'other dinoflagellates' in 2016, 2017, and 2018, respectively (Fig. 4). Cochlodinium spp. was a dominant member of the dinoflagellate community in 2008. However, it is important to note that since data are only available for fall of 2008 (Fig. S1), the contribution of diatoms to the yearly community may be underrepresented. This may be the opposite for 2011, in which data are missing from the fall and winter and therefore the contribution of dinoflagellates to the yearly community may be underrepresented (Fig. S1).

\subsection{Linking phytoplankton shifts toenvironmental variability}

The timing of the seasonal shift from a diatom-dominated phytoplankton community to a dinoflagellate-dominated community varied with the state of both the PDO and NPGO (Figs. $3 \&$ 5A-C, Fig. S4A-C).

[Insert Figure 4]

During the negative PDO period (positive NPGO), diatom communities dominated through the upwelling relaxation season and the shift to a dinoflagellate-dominated community occurred in October to November (Fig. 5B, Fig. S4B). In contrast, during the positive PDO period (negative NPGO), dinoflagellate-dominated communities appeared as early as July and persisted through the winter transition season (Fig. 5C, Fig. S4C).

In order to understand how the physical environment influenced the phytoplankton community composition during positive and negative PDO (and NPGO) periods, we (1) correlated the ratio of diatoms to dinoflagellates 
with the state of the PDO and NPGO (Table 1) as well as (2) explored our ability to predict the community state (dinoflagellate- ordiatom-dominated) using the upwelling wind-temperature parameter space averaged by month over the entire study period (Fig. 5D-I).

The linear model using the entire data set (e.g. all months across the time-series) revealed that the PDOdisplayed an insignificant, weak $\left(R^{2}=\right.$ 0.04) positive effect on the monthly averaged $\log _{10}$ dinoflagellate-diatom ratios (Table 1). Similarly, the NPGO had an insignificant, weak $\left(\mathrm{R}^{2}=0.08\right)$ negative association with the ratio. However, the strength of the correlations wasstrongly influenced by seasonality. While most seasons did not have a significant association between the climate indices and the dinoflagellatediatom ratio (Table 1), therewas significant correlation between both the PDO and NPGO and the dinoflagellate-diatom ratio during the fall relaxation period $\left(\mathrm{R}^{2}=0.32\right.$ and 0.40 , respectively; both $\mathrm{p}<0.01$; Table 1$)$. Additionally, the NPGO index displayed a significantly negative effect on the ratioduring both the June transition and peak upwelling season (Table 1).

The parameter space of upwelling winds and temperature revealed strong patterns with community type (dinoflagellate- or diatom- dominated). Diatoms tended to dominate the community during periods of stronger upwelling with low near-surface temperatures, while dinoflagellates were more dominant during periods of moderate upwelling and warmer temperatures (Fig. 5D-F). The positive PDO period (and negative NPGO) had more instances of dinoflagellate-dominated communities that occurred 
largely in the space of warmer temperatures and moderate upwelling (Fig. 5F and Fig. S4F, respectively).

The k-means clustering analyses identified 3 clusters: (A) lowupwelling wind, low-temperature; (B) moderate-upwelling wind, hightemperature; and (C) high-upwelling wind, low-temperature (Fig. 5G-I, Fig. S4G-I). Cluster A was always constituted by amix of dinoflagellate- and diatom-dominated months regardless of how the data were separated (i.e. Cluster A was never significantly diatom- or dinoflagellate-dominated; Table 2). In contrast, Cluster $\mathrm{C}$ was consistently, and significantly, diatomdominated across all analyses (Table 2). Cluster B displayed a

[Insert Figure 5]

[Insert Table 1]

[Insert Table 2]

higher proportion of dinoflagellate-dominated periods when all data were considered (Fig. 5G, Table 2) but was not significantly identified as either dinoflagellate- or diatom-dominated, relative to an equal probability (50\%) of one occurring. However, when only examining the data associated with a positive PDO (or negative NPGO) (Fig. 5I, Fig. S4), Cluster B had a significantly higher number of dinoflagellate-dominated months $(\mathrm{p}=0.03$, Table 2). In contrast, during a negative PDO (Fig. 5H), Cluster B had a significantly higher number of diatom-dominated months $(p=0.02$, Table 2).

\section{DISCUSSION}


This study provides the first seasonal and interannual characterization of SLO Bay's phytoplankton community. The long-term datasets presented here were collected as part of the Integrated Ocean Observing System (IOOS); specifically, CeNCOOS (Central and Northern California Ocean Observing System) and SCCOOS. These sampling programs provide an opportunity to explore the response of the base of the marine food web to environmental changes, with the goal of developing a predictive understanding within these ecosystems. In order to identify mean seasonal trends, it is crucial to consider multiple years because of the large interannual variability of oceanographic patterns in the CCS (Venrick 2012, Du et al. 2015, Walter et al.2018). Moreover, the length of these datasets is useful for understanding the role of interannual variability associated with lowfrequency climate oscillations as well as providing the opportunity to begin to understand how these systems might respond to future ocean conditions.

In general, the average seasonality of phytoplankton in SLO Bay mirrored that of the larger CCS (Kudela et al. 2005, Smayda \& Trainer 2010, Venrick 2012) with diatoms dominating the community during times of upwelling-favorable winds and decreased surface temperatures (April to May) and dinoflagellates dominating the community during times of weak upwelling winds and warmer surface waters (September to November; Fig. 1A). The seasonal maximum for total phytoplankton abundance occurred during the June transition period and was associated with a diatom-dominated community. This finding is consistent with the notion that moderate wind 
stress provides optimal conditions for the accumulation of phytoplankton biomass in nearshore environments within the CCS (Jacox et al. 2016). Peak surface chl $a$ concentrations, in contrast, coincided with the fall dinoflagellate-dominated period (Fig. 1B). The observed chl $a$ pattern likely reflects variations in the amount of pigment per cell, which is known to vary with cell size and type (Kalchev et al. 1996).

Looking at the taxa-specific patterns, the seasonal successions observed in our study largely followed Margalef's framework of changing wind forcing and nutrient concentrations (Margalef 1978, Margalef et al. 1979; Fig. 2). High abundances of Chaetoceros spp. in the spring are consistent with the notion that chain-forming diatoms are members of early successional communities, where waters are typically nutrient-rich yet still highly turbulent (Margalef 1978, Margalef et al. 1979, Smayda \& Trainer 2010). The greater contribution of Pseudo-nitzschia spp. to the community during the upwelling relaxation season is also consistent with other regions of the CCS (Lange et al. 1994, Kudela et al. 2010). Previous studies haveattributed this pattern to their ability to utilize alternative nitrogen sources (e.g. ammonia) or their high affinity for nitrate under low-nitrate concentrations (Seeyave et al. 2009, Loureiro et al. 2009). During the dinoflagellate-dominated fall, Cochlodinium spp. was a consistent contributor to the dinoflagellate community. This species has been a common bloomformer associated with deleterious HAB events in theregion (Jester et al. 2009, Kudela et al. 2010, Lewituset al. 2012) since its sudden emergence along the California Coast in 
2004 (Curtiss et al. 2008). Alexandrium spp., the HAB taxa which causes PSP (Horneret al. 1997, Jessup et al. 2009, Jones et al. 2017), represented a greater proportion of the dinoflagellate community in December.

Interannually, the phytoplankton community displayed taxonomic variation (Fig. 4). Within the diatoms, Chaetoceros spp. maintained a stable presence across all years. This finding is consistent with the characterization of this genus as a cosmopolitan bloom-former (Horner 2002). Pseudonitzschia spp. was a more variable contributor to the diatom community. We observed an increase in the relative abundance of Pseudo-nitzschia spp. in 2013 and 2014, whereas it represented a small proportion of the community in 2015. Interestingly, during 2015, an anomalous bloom of Pseudo-nitzschia australis was recorded at other HAB monitoring sites from Point Conception to North Washington (McCabe et al. 2016, Ryan et al. 2017), suggesting that local dynamics may play an important role in the patchiness of and discontinuities in coastwide blooms of this genera. Compared to diatoms, the dinoflagellate community composition was more variable between years, consistent with the notion that dinoflagellates form large, monospecific blooms, often exhibiting irregular abundance patterns (Gregorio \& Pieper 2000, Smayda \& Reynolds 2003, Smayda \& Trainer 2010). For example, Lingulodinium spp., was largely absent from most years, but had a large bloom in 2017. Similarly, Prorocentrum spp. while present in low numbers throughout the time-series, had large blooms in 2008 and 2018. These irregular blooms can have significant environmental consequences, such as 
low-oxygen events and toxin production (Paz et al.2004, Kudela et al. 2005, How ard et al. 2008).

One of the most striking patterns we observed across our decade-long time-series was the absence of a fall dinoflagellate-dominated period from 2009 through 2014 (Fig. 3), and we hypothesize this compositional shift occurred as a result of low-frequency climate variability. The CCS is impacted by a number of well-described climate patterns including El Niño Southern Oscillation (ENSO), the North Pacific GyreOscillation (NPGO), and the Pacific Decadal Oscillation (PDO), all of which are linked to one another (and not completely independent) through a complex interplay of oceanic and atmospheric physical processes and teleconnections (Di Lorenzo et al. 2008, 2013, Di Lorenzo \& Schneider 2010). Both the PDO and NPGO have been shown to drive low-frequency shifts in the physics and biology of the CCS at a number of trophic levels (Mantua et al. 1997, Di Lorenzo et al. 2008, Ohman et al. 2013). Positive PDO states (negative NPGO states) in the CCS are associated with weaker upwelling and hence warmer surface temperatures and decreased productivity (Di Lorenzo et al. 2008, Macias et al. 2012). Here, these climate modes appear to exert a strong influence on the seasonality of phytoplankton community succession and transition between diatom- and dinoflagellate-dominated periods. For example, the disappearance of the fall dinoflagellate-dominated period occurred during a consistently negative PDO (positive NPGO) state, while the return of a fall dinoflagellate-dominated period coincided with a shift to a positive phase of 
the PDO (negative phase of the NPGO). During the consistently positive PDO (negative NPGO) years, surface temperatures in SLO Bay were elevated, and dinoflagellate-dominated periods occurred earlier in the year (Fig. 5, Fig. S4). Conversely, extended negative PDO (positive NPGO) years exhibited cooler surface temperatures and had proportionally more diatom-dominated months with the seasonal fall dinoflagellate-dominated period nearly absent or occurring in later months (Fig. 5). We note that our data were derived from surface samples only; therefore, it is possible that subsurface dynamics differed from surface waters. However, we did not observe an increase in subsurface chl $a$ during this time period (Fig. S5, Fig. S4), suggesting that the dinoflagellate-dominated community was truly absent during this time-period and did not simply move to deeper depths.

Low-frequency climate variability has been shown to exert a strong influence on the seasonality of phytoplankton community succession at other locations. Within the southern California Cooperative Oceanic Fisheries Investigation (CalCOFI) region, Venrick (2012) described a shift in phytoplankton peak abundance towards summer months after 1999, which was the start of a cool (negative) phase of the PDO. Since peak abundance in this region is typically associated with the presence of diatoms, this observation is consistent with our observations in SLO Bay of a lengthening of the diatom-dominated period into later summer and early fall months during cool phases of the PDO (Fig. 5, Fig. S4). In 2002, a shift to a warm (positive) PDO state corresponded to an increase of dinoflagellate abundance during the 
upwelling season off the Oregon Coast; the dinoflagellate abundance declined again with the PDO shift to a negative state in 2008 (Du et al. 2015). While the PDO has long been used to explain physical and biological fluctuations and regime shifts in the CCS, the NPGO has been shown to be a better correlate with various oceanographic properties and mechanisms, including nutrient and phytoplankton concentrations (Di Lorenzo et al. 2008). In this study, we did not find a significant relationship between the PDO index and dinoflagellate-diatom ratio during upwelling months, but we did observe a significant relationship with the NPGO during that season (Table 1). Du et al. (2015) may have observed a stronger effect of the PDO on community composition during the upwelling season due to their more northerly location, as upwelling variability is better correlated with the NPGO (PDO) south (north) of $38^{\circ} \mathrm{N}$ (Chhak \& Di Lorenzo 2007, Di Lorenzo et al. 2008). Phytoplankton community composition (diatom:dinoflagellate ratio) in this study was best explained by the PDO and NPGO during the fall relaxation season (Table 1). It is important to note that the North Pacific Marine Heatwave, which led to large temperature anomalies and community wide effects on phytoplankton, first appeared in 2014 and lasted several years (Bond et al. 2015, Du \& Peterson 2018, Gómez-Ocampo et al. 2018). This coincided with the reemergence of the dinoflagellate-dominated fall periods in SLO Bay. However, marine heatwaves, and their multiyear persistence, have been linked to the underlying dynamics and increased coupling, of the PDO and NPGO (Joh \& Di Lorenzo 2017). These results highlight the strong 
influence of low-frequency basinscale climate variability on planktonic ecosystem dynamics at this site.

The observed shifts in phytoplankton community structure have important implications for the whole ecosystem. The timing of transition between phytoplankton community types is important because phenological variations can create ecological consequences throughout the food web (Edwards \& Richardson 2004). In addition, dinoflagellates and diatoms have vastly different influences on biogeochemical cycling. As a result of their silica frustule, diatoms sink more rapidly in the water column and therefore have higher sedimentation rates than dinoflagellates (Heiskanen 1998, Spilling et al. 2018). Diatoms have high trophic efficiency and promote population responses by large zooplankton (Aberle et al. 2007, Koski et al. 2008), whereas dinoflagellates have a more complex trophic role. Many taxa of dinoflagellates are mixotrophs, functioning both as primary producers and consumers. Furthermore, although a few diatom taxa are well-known for causing HABs (Rodger et al. 2011, Smith et al. 2018), dinoflagellates are disproportionately represented in the known HAB-forming taxa (Horner et al. 1997, Trainer et al. 2010, Lewitus et al. 2012). Toxins from HAB-forming taxa can have deleterious effects on upper trophic levels including fish and aquaculture (Jester et al. 2009, Rodger et al. 2011), seabirds (Jessup et al. 2009, Jester et al. 2009), invertebrates (Moore et al. 2010, Smith et al. 2018), and marine mammals (Scholin et al. 2000, McCabe et al. 2016).

Overall, the results of this study contribute a comprehensive 
characterization of the seasonal patternin an ecologically important, yet understudied location, while capturing a compositional shift in the phytoplankton community that may be representative of larger regions of the CCS. The response of diatoms and dinoflagellates to different environmental conditions (e.g. upwelling winds and surface temperatures) may provide an element of predictability for phytoplankton community composition. Our clustering analyses suggest that high-upwelling winds and low temperatures are consistent with diatom- dominated periods, whereas warmer temperatures produce conditions which allow for dinoflagellate-dominated periods. Furthermore, incorporating the state of NPGO and PDO into the analysis influences the extent to which temperature and upwelling wind can predict community type (Table 2). The link between phytoplankton community composition and the PDO/NPGO emphasizes the importance of considering large-scale climate patterns on local communities. Additionally, the response of dinoflagellate abundance to the positive PDO (negative NPGO) may provide insight about the potential impact of ocean warming on phytoplankton community composition in SLO Bay and other areas of the CCS. Thepositive PDO (negative NPGO) phase is characterized by warmer surface temperatures and hence increased stratification, features expected to increase with climate-change-driven ocean warming. Continued ocean warming could provide conditions favorable for dinoflagellate-dominated communities and HAB events.

Acknowledgements. We acknowledge support from the NOAA IOOS program 
through CeNCOOS (Shore Stations) and SCCOOS (HABs) for data collected at the Cal Poly Pier.We also thank a countless number of students, technicians, and former PIs (M. Moline and D. Wendt) on the IOOS grants for their help with operations, maintenance, and data collection over the years. Comments and suggestions from 3 anonymous reviewers greatly improved the manuscript.

\section{LITERATURE CITED}

Aberle N, Lengfellner K, Sommer U (2007) Spring bloom succession, grazing impact and herbivore selection of ciliate communities in response to winter warming. Oecologia 150:668-681

Anderson CR, Siegel DA, Brzezinski MA, Guillocheau N (2008) Controls on temporal patterns in phytoplankton community structure in the Santa Barbara Channel, California. J Geophys Res 113:C04038

Bejarano AC, Gulland FM, Goldstein T, St Leger J and others (2008)

Demographics and spatio-temporal signature of the biotoxin domoic acid in California sea lion (Zalophus californianus) stranding records. Mar Mamm Sci 24:899-912

Bond NA, Cronin MF, Freeland H, Mantua N (2015) Causes and impacts of the 2014 warm anomaly in the NE Pacific. Geophys Res Lett 42:3414-3420

Checkley DM, Barth JA (2009) Patterns and processes in the California Current System. Prog Oceanogr 83:49-64

Chhak K, Di Lorenzo E (2007) Decadal variations in the California Current upwelling cells. Geophys Res Lett 34: L14604 
Curtiss CC, Langlois GW, Busse LB, Mazzillo F, Silver MW(2008) The emergence of Cochlodinium along the California Coast (USA). Harmful Algae 7:337-346

Di Lorenzo E, Schneider N (2010) An overview of Pacific climate variability low-frequency modes of variability of the North Pacific. Technical Report 1-10. http://www. o3d.org/npgo/docs/Decadal-Intro.pdf

Di Lorenzo E, Schneider N, Cobb KM, Franks PJS and others (2008) North Pacific Gyre Oscillation links ocean climate and ecosystem change. Geophys Res Lett 35:L08607

Di Lorenzo E, Combes V, Keister JE, Strub PT and others (2013) Synthesis of Pacific Ocean climate and ecosystem dynamics. Oceanography $26: 68-81$

Du X, Peterson WT (2014) Seasonal cycle of phytoplankton community composition in the coastal upwelling system off central Oregon in 2009. Estuar Coast 37:299-311

Du X, Peterson WT (2018) Phytoplankton community structure in 2011-2013 compared to the extratropical warming event of 2014-2015. Geophys Res Lett 45:1534-1540

Du X, Peterson WT, O’Higgins L (2015) Interannual variations in phytoplankton community structure in the northern California Current during the upwelling seasons of 2001-2010. Mar Ecol Prog Ser $519: 75-87$

Edler L, Malte E (2010) The Utermöhl method for quantitative phytoplankton 
analysis. In: Karlson B, Cusack C, Bresnan E (eds) Microscopic and molecular methods for quantitative phytoplankton analysis. IOC Manuals and Guides No. 55. UNESCO, Paris p 13-20

Edwards M, Richardson AJ (2004) Impact of climate change on marine pelagic phenology and trophic mismatch. Nature 430:881-884

García-Reyes M, Largier JL (2012) Seasonality of coastal upwelling off central and northern California: new insights, including temporal and spatial variability.J Geophys Res, C, Oceans 117:C03028

Gómez-Ocampo E, Gaxiola-Castro G, Durazo R, Beier E (2018) Effects of the 2013-2016 warm anomalies on the California Current phytoplankton. Deep Sea Res II 151: 64-76

Gregorio DE, Pieper RE (2000) Investigations of red tides along the Southern California Coast. Bull South Calif Acad Sci 99:147-160

Greig DJ, Gulland FMD, Kreuder C (2005) A decade of live California Sea Lion (Zalophus californianus) strandings along the Central California Coast: causes and trends, 1991-2000. Aquat Mamm 31:11-22

Heiskanen AS (1998) Factors governing sedimentation and pelagic nutrient cycles in the northern Baltic Sea. Monographs of the Boreal Environment Research 8. Finnish Environment Institute, Helsinki Heisler J, Gilbert P, Burkholder J, Anderson D and others (2008) Eutrophication and harmful algal blooms: a scientific consensus. Harmful Algae 8:3-13

Horner RA (2002) A taxonomic guide to some common marine phytoplankton. 
Biopress, Bristol

Horner RA, Garrison DL, Plumley FG (1997) Harmful algalblooms and red tide problems on the U.S. west coast. Limnol Oceanogr 42:1076-1088

Howard MDA, Silver M, Kudela RM (2008) Yessotoxin detected in mussel (Mytilus californicus) and phytoplankton samples from the U.S. west coast. Harmful Algae 7: 646-652

Jacox MG, Hazen EL, Bograd SJ (2016) Optimal environmental conditions and anomalous ecosystem responses: constraining bottom-up controls of phytoplankton biomass in the California Current System. Sci Rep $6: 27612$

Jessup DA, Miller MA, Ryan JP, Nevins HM and others (2009) Mass stranding of marine birds caused by a surfactant-producing red tide. PLOS ONE 4:e4550

Jester R, Lefebvre K, Langlois G, Vigilant V, Baugh K, Silver MW (2009) A shift in the dominant toxin-producing algal species in central California alters phycotoxins in food webs. Harmful Algae 8:291-298

Joh Y, Di Lorenzo E (2017) Increasing coupling between NPGO and PDO leads to prolonged marine heatwaves in the Northeast Pacific. Geophys Res Lett 44:11663-11671

Jones T, Parrish JK, Punt AE, Trainer VL and others (2017) Mass mortality of marine birds in the Northeast Pacific caused by Akashiwo sanguinea. Mar Ecol Prog Ser 579: 111-127

Kalchev RK, Beshkova MB, Boumbarova CS, Tsvetkova RL, Sais D (1996) 
Some allometric and non-allometric relationships between chlorophyll$a$ and abundance variables of phytoplankton. Hydrobiologia $341: 235-245$

Keating N (2013) Seasonal variation of diatoms and dinoflagellates in Monterey Bay, CA determined by CHEMTAX analysis of HPLC pigment data. Master's thesis, California State University Monterey Bay, Moss Landing, CA, https://escholarship.org/uc/item/26394160

Koski M, Wichard T, Jonasdottir SH (2008) 'Good' and 'bad' diatoms: development, growth and juvenile mortality of the copepod Temora longicornis on diatom diets. Mar Biol 154:719-734

Kudela R, Pitcher G, Probyn T, Figueiras F, Moita T, Trainer V (2005) Harmful algal blooms in coastal upwelling systems. Oceanography (Wash DC) $18: 184-197$

Kudela RM, Seeyave S, Cochlan WP (2010) The role of nutrients in regulation and promotion of harmful algal blooms in upwelling systems. Prog Oceanogr 85:122-135

Lance GN, Williams WT (1967) A general theory of classificatory sorting strategies. II. Clustering systems. Comput J 10:271-277

Lange CB, Reid FMH, Vernet M (1994) Temporal distribution of the potentially toxic diatom Pseudo-nitzschia australis at a coastal site in Southern California. Mar Ecol Prog Ser 104:309-312

Large WG, Pond S (1981) Open ocean momentum flux measurements in moderate to strong winds. J Phys Oceanogr 11:324-336 
Lewitus AJ, Horner RA, Caron DA, Garcia-Mendoza E and others (2012) Harmful algal blooms along the North American west coast region: history, trends, causes, and impacts. Harmful Algae 19:133-159

Litchman E, Klausmeier CA (2008) Trait-based community ecology of phytoplankton. Annu Rev Ecol Evol Syst 39: 615-639

Litchman E, Klausmeier CA, Schofield OM, Falkowski PG (2007) The role of functional traits and trade-offs in structuring phytoplankton communities: scaling from cellular to ecosystem level. Ecol Lett 10:1170-1181

Longhurst AR (1995) Seasonal cycles of pelagic production and consumption. Prog Oceanogr 36:77-167

Loureiro S, Jauzein C, Garces E, Collos Y, Camp J, Vaque D (2009) The significance of organic nutrients to Pseudo-nitzschia delicatissima (Bacillariophyceae) nutrition. J Plankton Res 31:399-410

Macias D, Landry MR, Gershunov A, Miller AJ, Franks PJS (2012) Climatic control of upwelling variability along the Western North-American coast. PLOS ONE 7:e30436

MacQueen J (1967) Some methods for classification and analysis of multivariate observations. In: Proc 5th Berkeley Symp Mathematical Statistics and Probability, Oakland, CA. University of California Press, Berkeley, CA, p 281-297

Mantua NJ, Hare SR, Zhang Y, Wallace JM, Francis RC (1997) A Pacific decadal climate oscillation with impacts on salmon. Bull Am Meteorol Soc $78: 1069-1079$ 
Margalef R (1978) Life-forms of phytoplankton as survival alternative in an unstable environment. Oceanol Acta 1: 493-509

Margalef R, Estrada M, Blasco D (1979) Functional morphology of organisms involved in red tides, as adapted to decaying turbulence. In: Taylor DL, Seliger HH (eds) Toxic dinoflagellate blooms, Proc 2nd Int Conf. Elsevier, New York, NY, p 89-94

McCabe RM, Hickey BM, Kudela RM, Lefebvre KA and others (2016) An unprecedented coastwide toxic algal bloom linked to anomalous ocean conditions. Geophys Res Lett 43:10366-10376

McQuatters-Gollop A, Raitsos DE, Edwards M, Attrill MJ (2007) Spatial patterns of diatom and dinoflagellate seasonal cycles in the NE Atlantic Ocean. Mar Ecol Prog Ser 339:301-306

Moore SK, Mantua NJ, Hickey BM, Trainer VL (2010) The relative influences of El Niño-Southern Oscillation and Pacific Decadal Oscillation on paralytic shellfish toxin accumulation in northwest Pacific shellfish. Limnol Oceanogr 55:2262-2274

Ohman M, Barbeau K, Franks P, Goericke R, Landry M, Miller A (2013) Ecological transitions in a coastal upwelling ecosystem. Oceanography (Wash DC) 26:210-219

Paz B, Riobó P, Luisa Fernández M, Fraga S, Franco JM (2004) Production and release of yessotoxins by the dinoflagellates Protoceratium reticulatum and Lingulodinium polyedrum in culture. Toxicon 44:251-258

Peperzak L (2010) An objective procedure to remove observer-bias from 
phytoplankton time-series. J Sea Res 63:152-156

R Core Team (2017) R: a language and environment for statistical computing. R

Foundation for Statistical Computing, Vienna, www.R-project.org

Rodger HD, Henry L, Mitchell SO (2011) Non-infectious gill disorders of marine salmonid fish. Rev Fish Biol Fish 21: 423-440

Ryan JP, Kudela RM, Birch J, Blum M and others (2017) Causality of an extreme harmful algal bloom in Monterey Bay, California, during the 2014-2016 northeast Pacific warm anomaly. Geophys Res Lett $44: 5571-5579$

Scholin CA, Gulland F, Doucette GJ, Benson S and others (2000) Mortality of sea lions along the central California coast linked to a toxic diatom bloom. Nature 403:80-84

Schrader C (1981) Seasonal cycles of phytoplankton in rela tion to the hydrography of Monterey Bay. Master's thesis, contributions from Moss Landing Marine Laboratories No 51. Tech Pub 81-2

Seeyave S, Probyn TA, Pitcher GC, Lucas MI, Purdie DA (2009) Nitrogen nutrition in assemblages dominated by Pseudo-nitzschia spp., Alexandrium catenella and Dinophysis acuminata off the west coast of South Africa. MarEcol Prog Ser 379:91-107

Smayda TJ, Reynolds CS (2003) Strategies of marine dinoflagellate survival and some rules of assembly. J Sea Res 49:95-106

Smayda TJ, Trainer VL (2010) Dinoflagellate blooms in upwelling systems: Seeding, variability, and contrasts with diatom bloom behavior. Prog 
Oceanogr 85:92-107

Smith J, Connell P, Evans RH, Gellene AG and others (2018) A decade and a half of Pseudo-nitzschia spp. and domoic acid along the coast of southern California. Harmful Algae 79:87-104

Spilling K, Olli K, Lehtoranta J, Kremp A and others (2018) Shifting diatomdinoflagellate dominance during spring bloom in the Baltic Sea and its potential effects on biogeochemical cycling. Front Mar Sci 5:1-17

Strickland JDH, Parsons TR (1972) A practical handbook of seawater analysis, 2nd edn, Bulletin 167. Fisheries Research Board of Canada, Ottawa Sverdrup HU (1953) On conditions for the vernal blooming of phytoplankton. J Cons Cons Int Explor Mer 18: 287-295

Trainer VL, Pitcher GC, Reguera B, Smayda TJ (2010) The distribution and impacts of harmful algal bloom species in eastern boundary upwelling systems. Prog Oceanogr 85:33-52

Venrick EL (1998) Spring in the California Current: the distribution of phytoplankton species, April 1993 and April 1995. Mar Ecol Prog Ser $167: 73-88$

Venrick EL (2012) Phytoplankton in the California Current system off southern California: changes in a changing environment. Prog Oceanogr 104:46-58

Walter RK, Armenta KJ, Shearer B, Robbins I, Steinbeck J (2018) Coastal upwelling seasonality and variability of temperature and chlorophyll in a small coastal embayment. Cont Shelf Res 154:9-18 
Wasmund N, Kownacka J, Gobel J, Jaanus A and others (2017) The diatom/dinoflagellate index as an indicator of ecosystem changes in the Baltic Sea. 1. Principle and handling instruction. Front Mar Sci 4:22 Zeileis A (2004) Econometric computing with HC and HAC covariance matrix estimators. J Stat Softw 11:1-17 
Equation 1

$$
C=\left(\frac{N \times A}{V \times F \times A F \times D}\right) \times 1000
$$

Figure 1
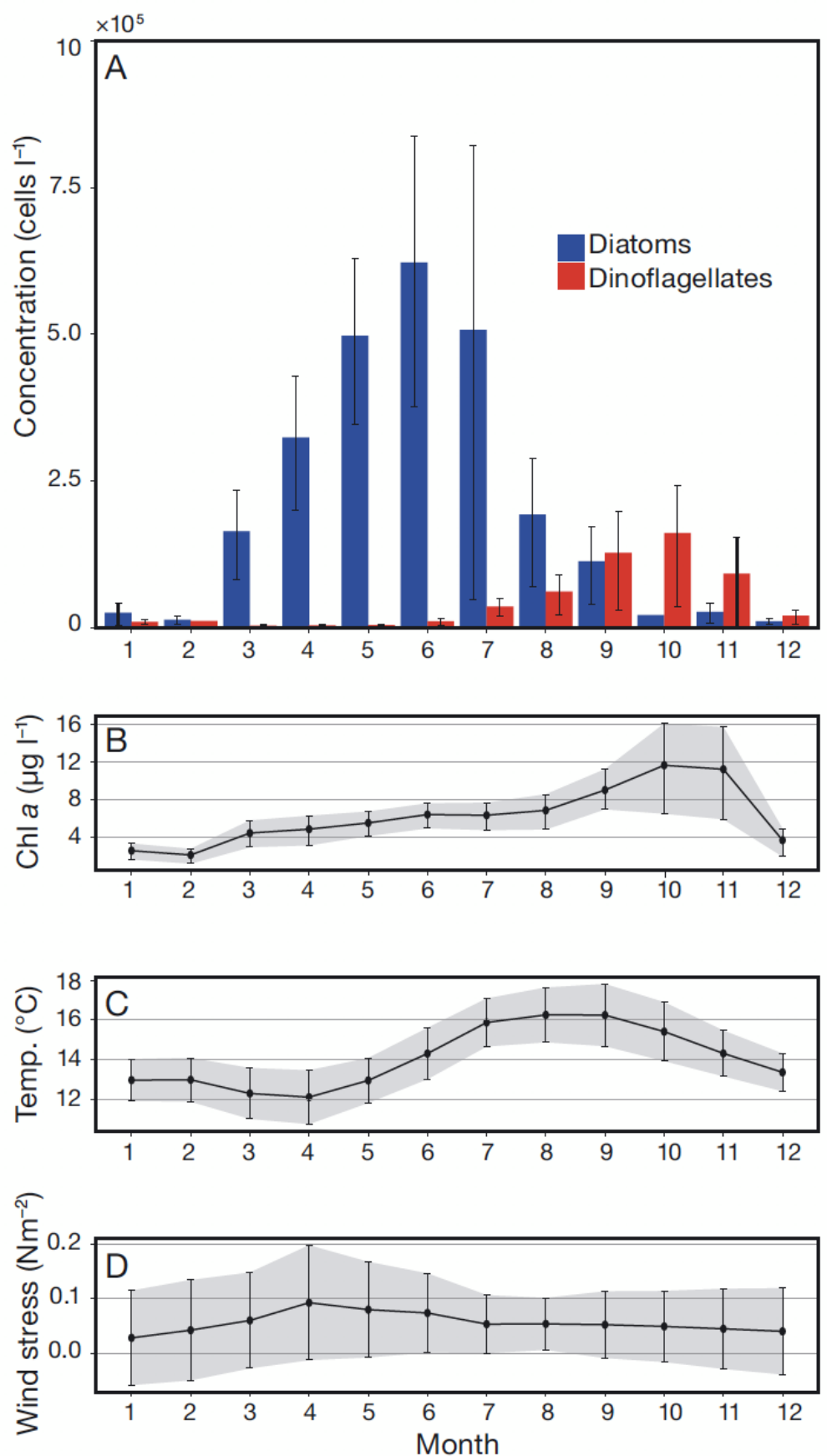
Fig. 1. (A) Average seasonal variability of diatom (blue) and dinoflagellate (red) concentrations. Error bars are bootstrapped 95\% confidence intervals of the mean. (B) Average seasonal variability of surface chl $a$. Error bars and shaded region represent empirical bootstrap for $95 \%$ confidence intervals of the monthly mean. Seasonal variability of $(\mathrm{C})$ near-surface water temperature and (D) upwelling-favorable wind stress, where shaded region is the $95 \%$ confidence interval of the mean. All data represent averages for each month across the study period

Figure 2

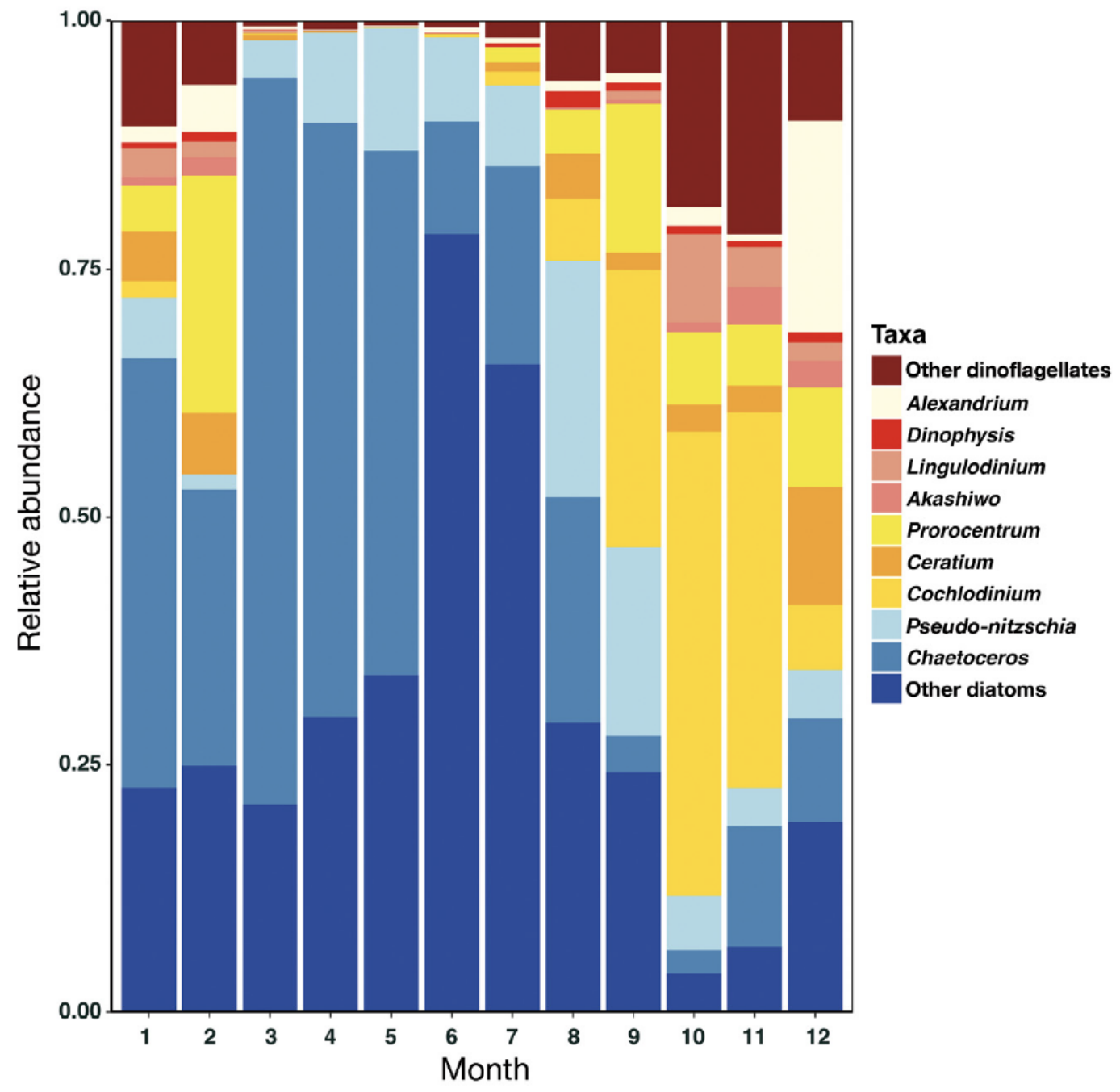


Fig. 2. Seasonal succession among HAB taxa. Data shown are the relative abundance of each taxa to the mean community averaged for each month across the study period (2008-2018). Relative abundance was calculated for the 11 taxonomic categories ( 9 genera and 2 'other' groups) by dividing the sum of each group's abundance in a given month by the total abundance (cells $1^{-1}$ ) summed across the 11 categories for that particular month. Warm colors represent dinoflagellates, and cool colors represent diatoms Figure 3
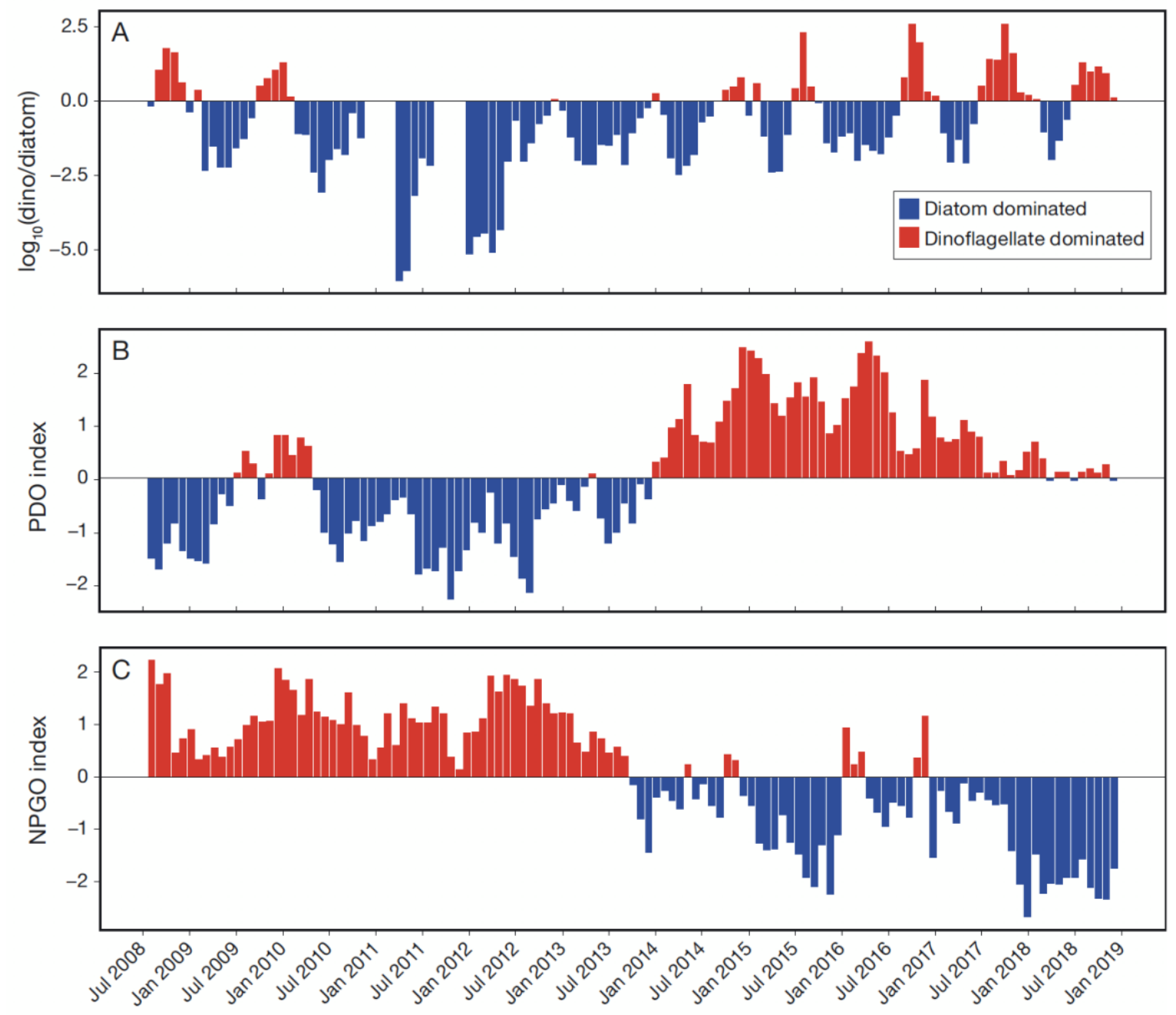
Fig. 3. (A) Interannual variability in the ratio of major phytoplankton taxa (dinoflagellates and diatoms) across the entire time-series. Each bar represents the $\log _{10}$ of the average ratio of dinoflagellates to diatoms for a given month. The bars are color-coded either blue for diatom-dominated months or red for dinoflagellate-dominated months. (B) Pacific Decadal Oscillation (PDO) index positive phase (red) and the negative phase (blue). (C) North Pacific Gyre Oscillation (NPGO) index positive phase (red) and the negative phase (blue). Note the missing phytoplankton data in 2011 (see Fig. S1 for data availability) 
Figure 4

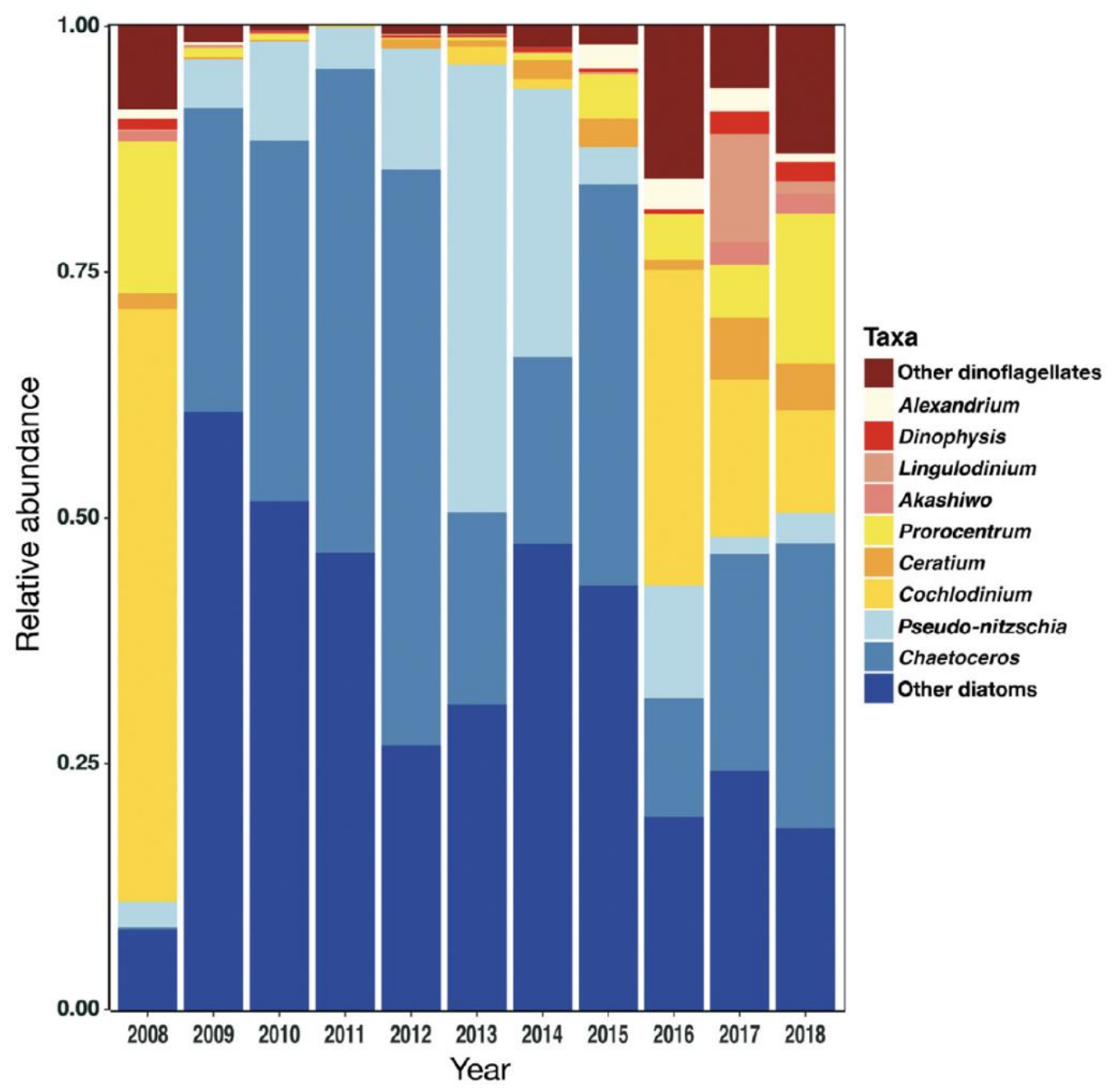

Fig. 4. Interannual variability of HAB taxa. Data shown are the relative abundance of each taxa to the mean community averaged for each year across the study period (2008-2018). All measurements of phytoplankton abundance were averaged within individual months over all years; then, the annual changes in the relative abundance were calculated by dividing the sum of abundance for each group (averaged by month) by the total yearly abundance. Warm colors represent dinoflagellates, and cool colors represent diatoms. Note 2008 and 2011 have missing data for large portions of the year and may 
underrepresent taxa which were present during missing data periods (see Fig.

\section{S1 for data availability)}

Figure 5
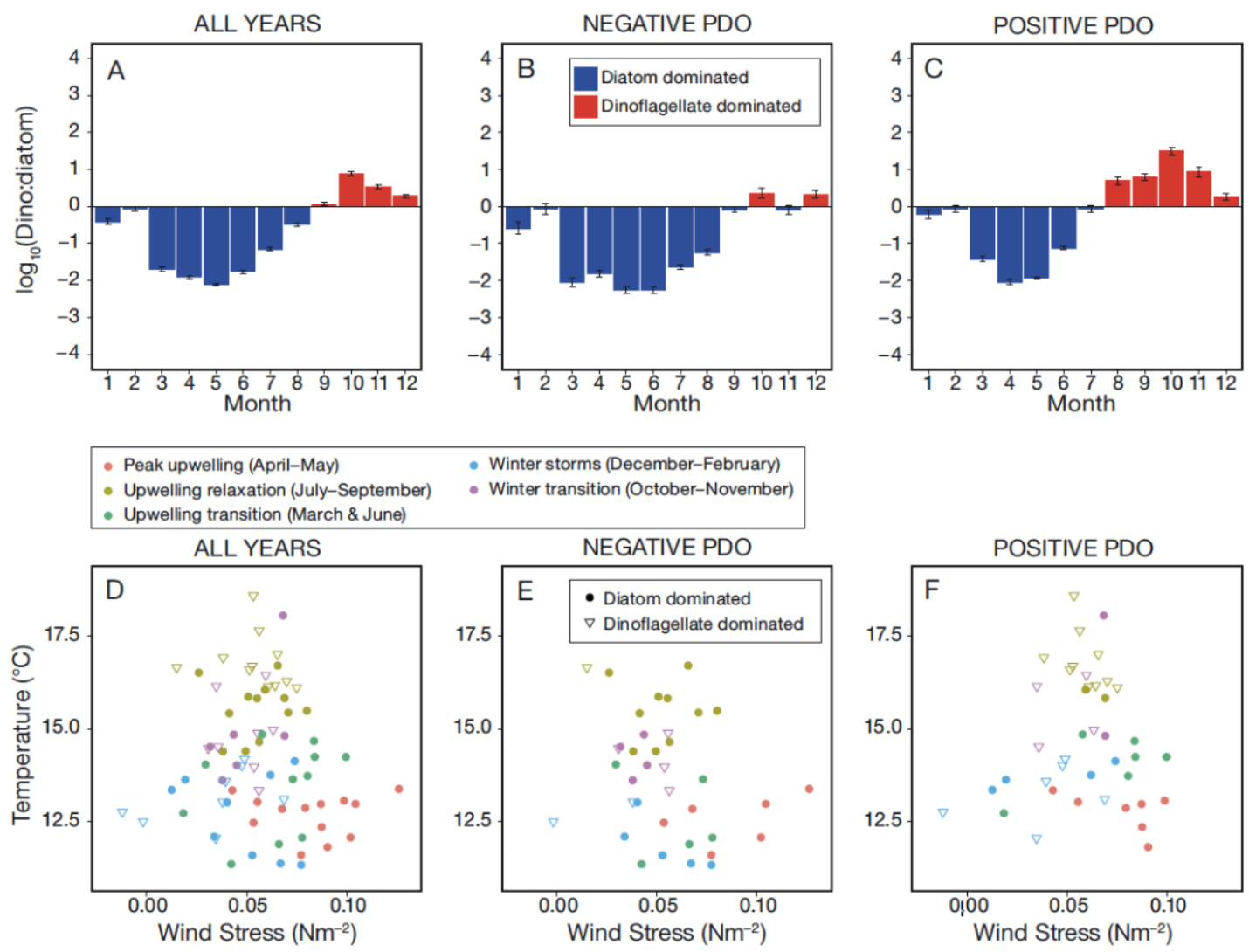

Winter storms (December-February)

- Winter transition (October-November)
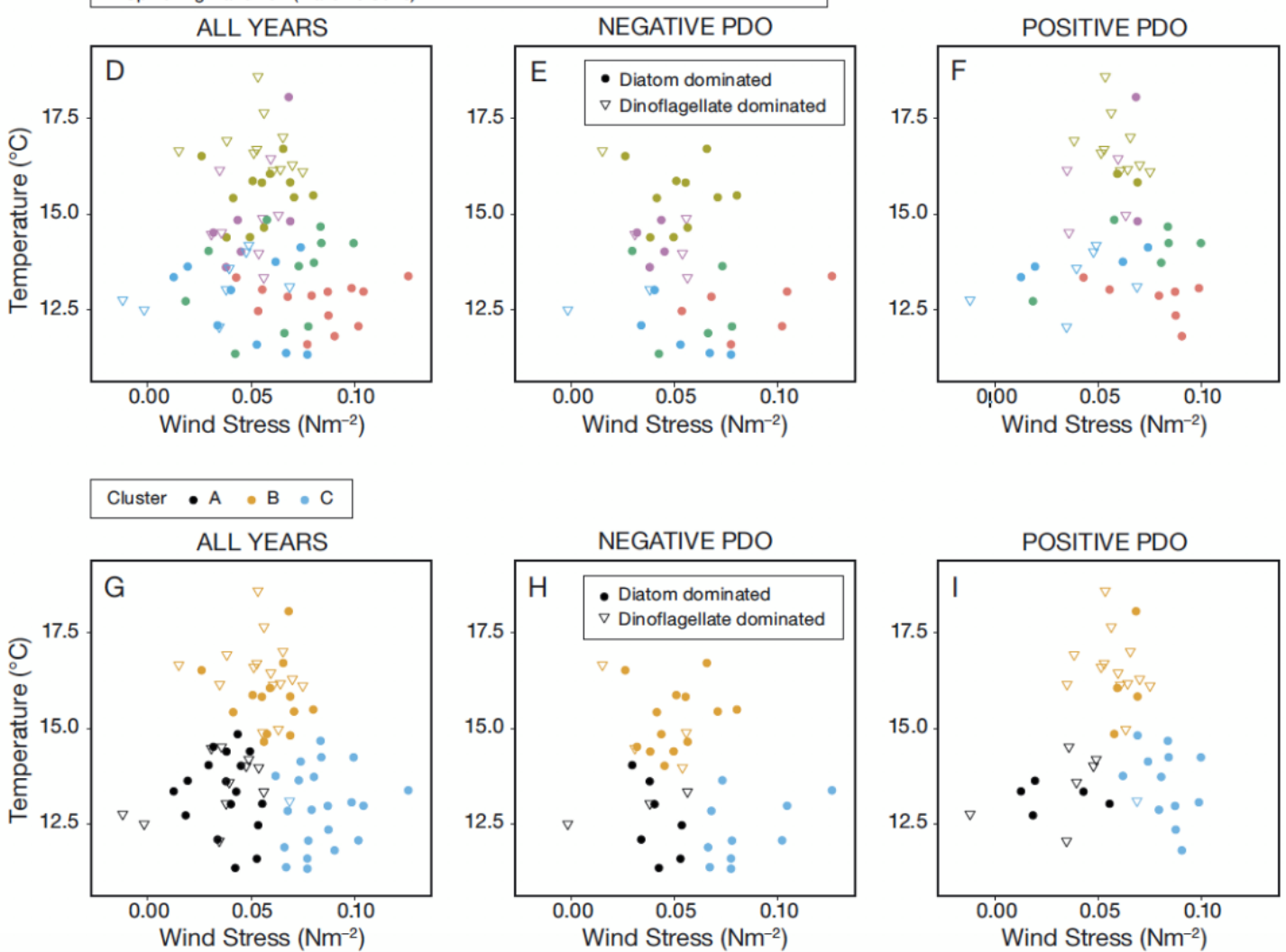

Fig. 5. Variation in seasonal community shift of major taxa linked to PDO.

Monthly mean ratio of dinoflagellate to diatom abundance over an average year 
including (A) all months over the entire dataset or only months that exhibit a (B) negative or (C) positive PDO state. See Fig. 3 for PDO monthly data. However, data in this figure (and for the clustering analyses) were separated based on the long-term mean state of the PDO (a shift from a negative mean state to a positive mean state occurred in January 2014; see Section 2.2.3 for details). Error bars are bootstrapped $95 \%$ confidence intervals for the mean. Blue: diatom dominance, red: dinoflagellate dominance. In panels $\mathrm{D}-\mathrm{F}$, monthly averages for upwelling-favorable wind stress and near-surface temperature are plotted as single points, for (D) all months and for months that exhibit a (E) negative or (F) positive PDO state. Points are color-coded by season rather than month (following Walter et al. 2018); diatom (circle) and dinoflagellate (triangle) dominated community. Panels G-I display the same data as D-F but the color indicates which cluster a point was assigned to during the independent k-mean analyses on the $(\mathrm{G})$ entire dataset and during months in a (H) negative or (I) positive PDO state. Significance of the proportion of each community type determined by exact binomial tests are available in Table 2 
Table 1

\begin{tabular}{|lrrr|}
\hline Model & Slope & $\mathrm{p}$ & $\mathrm{R}^{2}$ \\
\hline PDO & & & \\
All data & 0.30 & 0.20 & 0.04 \\
Winter storms & 0.42 & 0.33 & 0.10 \\
March transition & 0.36 & 0.21 & 0.22 \\
Peak upwelling & 0.54 & 0.16 & 0.18 \\
June transition & 0.34 & 0.14 & 0.16 \\
Fall relaxation & 0.60 & $<0.01$ & 0.32 \\
Winter transition & 0.16 & 0.66 & 0.02 \\
& & & \\
NPGO & & & \\
All data & -0.37 & 0.08 & 0.08 \\
Winter storms & -0.18 & 0.43 & 0.02 \\
March transition & -0.38 & 0.23 & 0.20 \\
Peak upwelling & -0.62 & 0.03 & 0.25 \\
June transition & -0.50 & 0.02 & 0.52 \\
Fall relaxation & -0.61 & $<0.01$ & 0.40 \\
Winter transition & -0.03 & 0.92 & $<0.01$ \\
\hline
\end{tabular}

Table 1. Results of the linear regression analysis between the monthly ratio of dinoflagellates to diatoms (response variable) and climate index (predictor variable). The modelcolumn indicates which months of data were included in each regression analyses. We adopted the seasonal framework developed by Walter et al. (2018) for this region, which includes the winter storms season (December-February), the peak upwelling season (April-May), and the upwelling relaxation period (July-September), with March and June representing upwelling transition months and October and November representing winter transition months 
Table 2

\begin{tabular}{|lccccr|}
\hline $\begin{array}{l}\text { Data } \\
\text { SS/total SS }\end{array}$ & Between & $\begin{array}{c}\text { Cluster } \\
\text { P(diatom- } \\
\text { dominated) }\end{array}$ & $\begin{array}{c}\text { Cluster's } \\
\text { of test }\end{array}$ & Direction & p \\
\hline Whole dataset & 0.65 & A & 0.61 & Dia-dom & 0.17 \\
& & B & 0.46 & Dino-dom & 0.43 \\
PDO-negative & 0.63 & C & 0.96 & Dia-dom & $<0.01$ \\
& & A & 0.70 & Dia-dom & 0.17 \\
PDO-positive & 0.72 & B & 0.77 & Dia-dom & 0.02 \\
& & C & 1.00 & Dia-dom & $<0.01$ \\
NPGO-negative & 0.71 & B & 0.46 & Dino-dom & 0.50 \\
& & C & 0.24 & Dino-dom & 0.03 \\
& & A & 0.92 & Dia-dom & $<0.01$ \\
NPGO-positive & 0.63 & C & 0.23 & Dia-dom & 0.40 \\
& & A & 0.92 & Dino-dom & 0.03 \\
& & B & 0.73 & Dia-dom & $<0.01$ \\
& & C & 1.00 & Dia-dom & 0.25 \\
& & & Dia-dom & 0.06 \\
& & & & & $<0.01$ \\
\hline
\end{tabular}

Table 2. Results of exact binomial tests on clusters identified from the kmeans clustering analysis. The data column indicates which data were used for each k-means clustering analysis, which identified the clusters independently. The exact binomial test compared if the cluster's community type distribution (dinoflagellate- or diatom-dominated) was significantly different $(p<0.05)$ from a symmetrical binomial distribution. P(Diatom-Dominated) is each cluster's proportion of diatom-dominated months. The direction (direction of test) column indicates if the 1-tailed tests were for a diatom-dominated or dinoflagellate-dominated community. SS: sum of squares. Dia-, dino-dom: diatom-, dinoflagellate-dominated 